\title{
Intergranular crack tip oxidation in a Ni-base superalloy
}

\author{
L. Viskari ${ }^{1}$, Magnus Hörnqvist ${ }^{1,2}$, K. L. Moore ${ }^{3}$, Y. Cao ${ }^{4}$, K. Stiller ${ }^{1}$ \\ ${ }^{1}$ Department of Applied Physics, Chalmers University of Technology, SE-411296, Göteborg, Sweden \\ ${ }^{2}$ Research and Technology Centre, GKN Aerospace Engine Systems, SE-46181, Trollhättan, Sweden \\ ${ }^{3}$ Department of Materials, University of Oxford, Parks Road, Oxford OX1 3PH, UK \\ ${ }^{4}$ Department of Materials and Manufacturing Technology, Chalmers University of Technology, \\ SE-411296, Göteborg, Sweden
}

Corresponding author: Krystyna Stiller (stiller@chalmers.se)

\begin{abstract}
High temperature intergranular crack tip oxidation under a single $600 \mathrm{~s}$ long sustained tensile load at $700{ }^{\circ} \mathrm{C}$ was studied for the Ni-base superalloy Allvac 718Plus. High-resolution analytical techniques showed oxidation to take place at and immediately ahead of the tip of an open crack, forming a closed but layered oxide structure about the prior (now oxidized) grain boundary. Near the prior grain boundary the oxide is Ni-rich with a Co-enriched layer furthest away from the metal and a $\mathrm{Fe}$ enriched region below this. A Cr-rich oxide is present below the outer Ni-rich oxides throughout the crack, also in the direction of crack growth. This is believed to have a hindering effect on oxidation ahead of the crack. $\mathrm{Ni}_{3}(\mathrm{Nb}, \mathrm{Al}) \gamma^{\prime}$ precipitates close to the grain boundaries were found to oxidize and form regions of near-stoichiometric $\mathrm{NiO}$ within the oxide layers. Remaining constituents of $\gamma^{\prime}$ (e.g. Al and $\mathrm{Nb}$ ) were found to be enriched in the surrounding oxidized matrix and also to produce thin oxide layers near the interface between unoxidized metal and the Cr-rich oxide. The formation of the crack tip oxides is discussed with regard to thermodynamics, kinetics and the influence of applied mechanical load.
\end{abstract}

Keywords: Oxygen; Diffusion; Atom probe tomography; Transmission electron microscopy; Secondary ion mass spectroscopy.

\section{Introduction}

Intergranular time-dependent crack growth in superalloys is known to be promoted by oxygen-rich environments at high temperatures (typically $>500{ }^{\circ} \mathrm{C}$ ) in combination with sustained loads or certain low frequency fatigue cycles. This is in contrast to the transgranular cycle-dependent behaviour observed in environments with low oxygen content (e.g. vacuum or inert gas environments such as Ar), lower temperatures or at higher fatigue frequencies (typically $>10 \mathrm{~Hz}$ ). This type of crack growth has been known and studied for several decades: see e.g. [1-5] for characteristic publications from 1970s and 1980s and also the more recent comprehensive summaries by Woodford [6] and Pineau [7]. Yet, the details of crack growth are still not well understood today with a specific lack of information regarding the behaviour and influence of oxygen at the crack tip. Increased knowledge of the events at the crack tip is not only important for understanding the mechanisms of this type of crack growth. It also allows for improved constitutional fatigue life modelling in industrial applications, such as gas turbine engines, where high temperature fatigue cycles with sustained loads or low fatigue frequencies need to be considered.

The effect of oxygen on crack growth has typically been approached by studies of oxides in the crack wake $[8,9]$ or studies of the crack tip by techniques that by today's standards offer low spatial resolution [10]. Crack growth mechanisms suggested in literature are largely based on such experiments with little detailed insight to what occurs at the very crack-tip. In literature, two main mechanisms are often proposed: dynamic embrittlement (DE) and stress-accelerated (sometimes also termed strain-assisted) grain boundary oxidation (SAGBO). Dynamic embrittlement is stated to occur by grain boundary diffusion of oxygen ahead of a crack tip, causing decohesion and consequently 
cracking of the grain boundary under load [11]. Oxidation is suggested to take place only following cracking by DE. Conversely, SAGBO advocates fracture of an oxidized grain boundary ahead of a crack tip $[4,12]$. Nevertheless, for both mechanisms the presence of oxygen, an applied mechanical load and high temperatures are all considered prerequisites for cracking to occur. In order to neutrally discuss the results and interpretations in the present work the term sustained load crack growth (SLCG) will be used.

In the present work, SLCG was studied with specific attention given to the detailed effects and influence of oxygen at the crack tip. High-resolution analytical studies were performed down to atomic level using current state-of-the-art techniques to investigate the effect of oxygen on the local crack tip microstructure and chemistry. Focussed ion beam (FIB) milling was used to prepare sitespecific samples for transmission electron microscopy (TEM) and atom probe tomography (APT). Additionally, an ${ }^{18} \mathrm{O}$-enriched environment was used during the sustained load period to be able to distinguish between oxygen interaction that occurred during testing from that which might have occurred during subsequent sample preparation and storage (in which case ${ }^{16} \mathrm{O}$ would dominate given its natural abundance). The samples exposed to ${ }^{18} \mathrm{O}$ were analysed with APT and high-resolution secondary ion mass spectroscopy (SIMS), as both are mass-spectroscopy techniques and therefore have the ability to distinguish between different $\mathrm{O}$ isotopes.

This paper presents detailed investigations of crack tip oxidation, using the aforementioned methods, in the wrought Ni-base superalloy Allvac 718Plus. Details of oxidation and oxygen distribution at the crack tip are specifically discussed as well as the behaviour and diffusivity of oxygen under the influence of mechanical load.

\section{Experimental}

\section{Material}

Studies were undertaken on the wrought Ni-based alloy Allvac 718Plus (at.\%: $51.6 \mathrm{Ni}, 19.9 \mathrm{Cr}, 9.9$ Fe, 8.9 Co, 3.4 Nb, 3.1 Al, 1.6 Mo, 0.9 Ti, 0.32 W, 0.12 Si, 0.10 C, 0.05 Mn, 0.01 P, 0.027 B, <0.001 S) obtained as wrought bar from ATI Allvac (Monroe, NC, USA). The alloy was heat treated to an age hardened condition virtually free of plate-like grain boundary phase, as the authors' previous findings [13] have shown such condition to be more susceptible for SLCG than conventional microstructures containing such phase. It should be noted that reports on the crystal structure of the plate-like grain boundary phase in Allvac 718Plus are not fully resonant. The phase is attributed to being the orthorhombic $\delta$-phase $[14,15]$ (typical for Alloy 718) as well as an hexagonal structure [16, 17]. Nevertheless, the heat treatment was performed as follows, with water quenching (WQ) and furnace cooling (FC) between steps: $1040{ }^{\circ} \mathrm{C} / 1 \mathrm{~h}(\mathrm{WQ})+788^{\circ} \mathrm{C} / 8 \mathrm{~h}(\mathrm{FC})+704{ }^{\circ} \mathrm{C} / 8 \mathrm{~h}(\mathrm{FC})$. The first solution step brings all phases but carbides into solution. The latter two aging steps precipitate the $\gamma^{\prime}$ $\mathrm{Ni}_{3}(\mathrm{Al}, \mathrm{Nb})[18]$ hardening precipitates (typically $10-100 \mathrm{~nm}$ in size). The resulting microstructure is shown in Figure 1 where the grain boundaries are seen free of plate-like precipitates. Mostly intragranular $\mathrm{NbC}$ and $\mathrm{TiC}$ can be additionally observed as bright and dark particles, respectively. The hardness of this condition was measured at 429 HV10 kg which is in line with what is expected of Allvac 718Plus. Single edge notched (SEN) mechanical testing specimens were machined with waist cross-sections of $3 \times 8 \mathrm{~mm}$. The U-shaped $0.2 \mathrm{~mm}$ deep through-thickness notch was produced by electric discharge machining (EDM) on the $3 \mathrm{~mm}$ side.

\section{Mechanical testing}

Mechanical testing was performed using a MTS model 661 hydraulic rig with a custom designed environmental chamber, allowing a controlled environment (introduction of ${ }^{18} \mathrm{O}$ and Ar), induction heating of the specimen (at a rate of $70{ }^{\circ} \mathrm{C} \mathrm{s}^{-1}$ ) and crack growth monitoring using the direct current 
potential drop (PD) method using a 10 A direct current introduced at the grips. The PD probes were spot welded across the EDM notch and reference probes were likewise attached to the back face of the specimen, away from the cracked cross-section. The ratio of the PD across the crack and the reference probes allowed monitoring of the crack growth independent of any variations in temperature and current, using an experimentally obtained calibration function to relate crack area to PD signal.

A $2 \mathrm{~mm}$ long fatigue crack was generated in two stages, first at room temperature (RT) and then at $700{ }^{\circ} \mathrm{C}$, using a $10 \mathrm{~Hz}$ triangular waveform and a load ratio $R=P_{\min } / P_{\max }=0.05$. The maximum load in the final stage was $4 \mathrm{kN}$. Once the fatigue crack was generated, a mixture of ${ }^{16} \mathrm{O}_{2}$ and ${ }^{18} \mathrm{O}_{2}$ at $1: 1$ mass ratio was introduced to the specimen chamber as a single mixed $\mathrm{O}_{2}$ flow while maintaining 700 ${ }^{\circ} \mathrm{C}$ and zero load. The $\mathrm{O}_{2}$ flow rate was $50 \mathrm{ml} \mathrm{s}^{-1}$ at 2 bar and the chamber volume (deducting the volume occupied by the sample) was approximately $40 \mathrm{ml}$, meaning that the chamber environment was essentially purged every 0.8 seconds. A tensile load of $4 \mathrm{kN}$ (nominal stress of $167 \mathrm{MPa}$, corresponding to an approximate initial stress intensity factor value of $K_{\max }=20 \mathrm{MPa} \mathrm{m}{ }^{1 / 2}$ ) was applied and held constant for $600 \mathrm{~s}$, during which time the crack growth was continuously monitored through the PD signal. After $600 \mathrm{~s}$ the chamber environment was immediately changed from the $\mathrm{O}_{2}$ mixture to forced convection cooling in $\operatorname{Ar}\left(>500 \mathrm{ml} \mathrm{s}^{-1}\right.$ at 2 bar), while simultaneously turning off the induction heating and releasing the mechanical load to zero. On cooling, the sample temperature was registered below $500{ }^{\circ} \mathrm{C}$ within 15 seconds and approximations by finite element calculations show that the temperature difference between the specimen surface and interior is negligible during cooling. Thus, any ${ }^{18} \mathrm{O}$ encountered in excess to the natural isotope abundance $(0.2 \%)$ must have been incorporated into the sample during the $600 \mathrm{~s}$ long period of sustained load and this can readily be studied using the APT and SIMS techniques.

\section{Analysis methods}

The general methodology for sample preparation and microanalysis of crack tips has been presented in previous work [19]. The investigations here are performed based on these methods and deviations are explicitly stated.

An FEI Quanta 200 field emission gun scanning electron microscope (FEG-SEM) was used to study the crack path by backscattered electron (BSE) imaging. Crack cross-sections were polished to 0.05 $\mu \mathrm{m}$ colloidal silica finish. TEM analyses of the oxides were performed to investigate their structure and chemistry. A Philips CM200 FEG-TEM was used with an Oxford INCA energy dispersive X-ray (EDX) spectroscopy system. EDX analyses were performed using scanning TEM (STEM) mode.

A Cameca NanoSIMS50 was used to study the sub-micron-scale oxygen distribution at the crack tips prior to APT analysis. A $16 \mathrm{keV} \mathrm{Cs}{ }^{+}$primary ion beam with a probe current of $0.4-0.5 \mathrm{pA}$ was scanned over the sample surface using the smallest aperture (D1-4, $200 \mu \mathrm{m}) .8 \mu \mathrm{m} \times 8 \mu \mathrm{m}$ images with a resolution of $256 \times 256$ were acquired with a dwell time of $10 \mathrm{~ms}$ per pixel for the ${ }^{16} \mathrm{O}^{-},{ }^{18} \mathrm{O}^{-}$and secondary electron signals. The detector positioning for ${ }^{18} \mathrm{O}^{-}$was calibrated using a sample with a known high concentration of ${ }^{18} \mathrm{O}$. NanoSIMS maps are presented in a linear colour scale, with red and yellow regions indicating higher counts and blue and black regions indicating lower counts.

APT was used for the most detailed studies of local chemistry and microstructure at the crack tips. APT also allows distinction between ${ }^{18} \mathrm{O}$ and ${ }^{16} \mathrm{O}$ at levels down to ppm, however, the spatial resolution of APT (near atomic resolution [20]) is far higher than that of NanoSIMS. Laser pulsed APT was performed at $0.5 \mathrm{~nJ}$ for bulk samples to reduce peak overlap between $\mathrm{Ni}$ and $\mathrm{Nb}$, as per [18]. Oxide acquisitions in this work were however performed at lower laser energies of 0.3-0.4 nJ to avoid extensive heating of the specimen due to the low thermal conductivity of the oxides.

Site-specific preparation of TEM and APT samples was performed on a FEI Strata 235 combined focussed ion beam (FIB) and SEM instrument (FIB-SEM) using the methodology shown in [19]. 
X-ray photoelectron spectroscopy (XPS) was performed using a PHI5500 instrument with a monochromatised $\mathrm{Al}_{\mathrm{K} \alpha}(1486.6 \mathrm{eV}) \mathrm{X}$-ray source. The acquisition conditions used were: $23.5 \mathrm{eV}$ pass energy, $45^{\circ}$ take off angle, and $0.1 \mathrm{eV} / \mathrm{step}$. The Fe 2p1/2, Co 2p1/2 and Al 2s core level photoelectron peaks were selected for quantification to avoid issues with peak overlaps. Depthprofiling was performed using Ar-ions at $4.0 \mathrm{keV}$, with the sputtering rate calibrated using $\operatorname{Ta}_{2} \mathrm{O}_{5}$.

\section{Results}

All results correspond to studies of cracks produced during the sustained load period at $700{ }^{\circ} \mathrm{C}$, verified by the ${ }^{18} \mathrm{O}^{-16} \mathrm{O}^{-}$ratio. Crack growth during sustained load was fully intergranular with intergranular crack branching, as exemplified in Figure 2. The sustained load crack growth rate was essentially constant at approximately $6 \cdot 10^{-4} \mathrm{~mm} \mathrm{~s}^{-1}$.

Figure 3 (a) shows an SEM BSE image of a sustained load crack tip. The corresponding NanoSIMS image in Figure 3 (b) shows the ${ }^{18} \mathrm{O}$-signal to exclusively originate from the intergranular crack. The ${ }^{18} \mathrm{O}^{-16} \mathrm{O}^{-}$intensity ratio was measured close to $1: 1$ all the way to the very crack tip, i.e. the mass ratio used for the sustained load environment. This confirms that the crack and its oxides were created during the sustained load period and that oxygen is able to access the crack tip during this time. It is noteworthy that the observed O-rich region appears slightly broader than estimated by the effect of the beam (diameter $<70 \mathrm{~nm}$ ) being scanned over the oxide. Notwithstanding this broadening, neither the grain boundary ahead of the crack nor the flanking grains show enrichment of ${ }^{18} \mathrm{O}$. The SEM BSE studies also showed slight plastic deformation (spanning up to some microns) in the grains flanking the cracks and also in the grain boundary region ahead of the intergranular crack. Oxidized $\mathrm{Nb}$ - and $\mathrm{Ti}$ carbides, typically some microns in size and some tens of microns apart, and also some rare undissolved plate-like particles were observed in the intergranular crack paths in the cross-sectioned samples and on intergranular fracture surfaces (the latter for samples fractured by three-point bending following mechanical testing to allow access to the crack surface). These results are in line with previous reports [13] on Allvac 718Plus. As the carbides are relatively scarce and no carbides were in fact encountered in the crack tips analysed, they are considered of less significance for the present investigation and will be addressed as part of a separate publication.

To further verify the findings on the presence of oxygen by SIMS analyses, APT was performed on grain boundaries less than $0.5 \mu \mathrm{m}$ ahead of oxidized crack tips. These analyses revealed that neither the grain boundaries nor the adjacent grains exhibit any increased levels of oxygen $(<0.03$ at.\%) compared to untested material. However, as in previous work [18], segregation of B and $\mathrm{P}$ to the grain boundary was observed (Figure 4). Especially the B concentration at this boundary was found to be high (0.6 at.\%) compared to the nominal B content in the material (0.027 at.\%).

Figure 5 shows XPS depth profiles of the crack surface oxides obtained in the wake of a crack in a specimen that was broken apart (as per above). The XPS analysis was targeted some $0.3 \mathrm{~mm}$ back from the crack tip and the relatively large spot-size of the XPS (approximately $0.5 \mathrm{~mm}$ in diameter) allowed averaging of oxide scale thicknesses and composition. The oxide in the crack wake is clearly layered with a $\mathrm{Cr}$-rich layer near the metal and outer Ni-rich layers with varying levels of $\mathrm{Fe}$ and $\mathrm{Co}$. Also $\mathrm{Nb}$ and $\mathrm{Al}$ are present near the oxide/metal interface.

The structure and chemistry of the closed crack tip oxide was studied using TEM as shown in Figure 6. The contrast from the oxide in the TEM bright-field (BF) image in Figure 6 (a) in combination with the ring-like selected area diffraction (SAED) pattern in Figure 6 (b) suggest that the scale is polycrystalline with grains some tens of nanometres in size. TEM also showed plastic deformation near the crack up to some microns away from the crack, as also observed by SEM. The TEM-EDX elemental ratio maps in Figure 6 (c) show the positions of: Ni-enriched region (green), $\mathrm{Cr}$ and $\mathrm{O}$ at 2:3 ratio (red) and $\mathrm{Ni}+\mathrm{Fe}$ and $\mathrm{O}$ at 1:1 ratio (blue). The $\mathrm{Cr}$-rich oxide is situated at the oxide/matrix interface below the $\mathrm{Ni} / \mathrm{Fe}$-rich oxide and also at the very tip of the oxide, ahead of the $\mathrm{Ni} / \mathrm{Fe}$ oxide in the crack growth direction. The Cr-rich oxide is flanked by the Ni-enriched regions. The time for 
oxide formation in this region was estimated to less than $30 \mathrm{~s}$ accounting for the nominal crack growth rate, possible local crack arresting and also the convection cooling period of $15 \mathrm{~s}$ in Ar.

To investigate the oxide growth kinetics the thicknesses of the Cr- and Ni-rich oxide layers were measured in the crack wake at approximated exposure times (given by the time elapsed since the crack front passed the particular region). The exposure times were estimated to be in the order of 30 , 300 and 3000 seconds, respectively, with greater uncertainty for the $3000 \mathrm{~s}$ value. The $30 \mathrm{~s}$ oxide thickness was measured by TEM within the closed oxide region and thus half the total closed oxide thickness was considered. The $300 \mathrm{~s}$ oxide was that analysed by XPS in the crack wake. The present work does not allow exposures longer than $600 \mathrm{~s}$ to be studied, which is why the $3000 \mathrm{~s}$ oxide thickness was derived from XPS analysis presented in previous work [13] in a highly similar condition of Allvac 718Plus without plate-like grain boundary phase. The conversion from sputter time to depth for both XPS analyses was calibrated using the sputter rate of $\mathrm{TaO}_{2}$, not the actual alloy, and also the rough fracture surface analysed may have led to slight overestimation of the oxide thickness. Hence the sputtering depth scale for the XPS measurements is slightly uncertain and the absolute values obtained at 300 and $3000 \mathrm{~s}$ are therefore not strictly comparable to the results from the TEM investigation. However, the error is expected to be small for short sputter times and the measurements allow at least an indication of the thicknesses of the respective oxides at short times. Also, the oxide thickness ratio $\mathrm{NiO}: \mathrm{Cr}_{2} \mathrm{O}_{3}$ can be used to study the development of the oxide scales with time, see Figure 7. The NiO: $\mathrm{Cr}_{2} \mathrm{O}_{3}$ ratio decreases drastically between 30 and $300 \mathrm{~s}$ and then remains essentially constant up to $3000 \mathrm{~s}$. Comparing the oxide growth between 300 and $3000 \mathrm{~s}$ measured from the XPS profiles, assuming the same sputter rate in both cases, it can be seen that both oxides have grown, the $\mathrm{Cr}_{2} \mathrm{O}_{3}$ oxide about twice as much as the $\mathrm{NiO}$.

More detailed studies of the oxide close to the oxide tip were performed using APT. The mass spectrum obtained from the oxide is very complex given not only the large number of alloying elements but also the numerous oxygen containing molecular ions (for example: $\mathrm{AlO}^{\mathrm{n}+}, \mathrm{NiO}^{\mathrm{n}+}$, $\mathrm{Al}_{2} \mathrm{O}_{3}{ }^{\mathrm{n+}}, \mathrm{NbO}_{2}{ }^{\mathrm{n}+}$ and others) and also overlapping peaks (e.g. $\mathrm{Ni}^{2+}$ and $\mathrm{Nb}^{3+}, \mathrm{O}_{2}{ }^{+}$and $\mathrm{CrO}^{2+}$, etc). The use of ${ }^{18} \mathrm{O}$ further complicates matters as the oxygen containing molecular ions are not restricted to e.g. $\mathrm{Ni}^{16} \mathrm{O}$, but may also be $\mathrm{Ni}^{18} \mathrm{O}$, and additionally $\mathrm{Ni}^{\left({ }^{(16+18)}\right.} \mathrm{O}_{2}$, yielding a large number of high intensity peaks in the mass spectrum.

These conditions made precise quantification of oxygen content in the oxide scale difficult. In ordinary circumstances, a commercial program (IVAS) can be used to decompose overlapping peaks based on the natural abundance of the isotopes. In this work, due to the un-natural abundance of ${ }^{18} \mathrm{O}$, such decomposition could not be performed using IVAS. Thus, the presented O-contents in the observed oxides (Table 1) are slightly underestimated. On the other hand, the presence of the peak at $17 \mathrm{Da}$, originating from $\left({ }^{16} \mathrm{O}+{ }^{18} \mathrm{O}\right)^{2+}$ molecular ions, allowed the otherwise impossible differentiation between $\mathrm{O}^{+}$and $\mathrm{O}_{2}{ }^{2+}$ signals because of the very low ${ }^{18} \mathrm{O}$ abundance $(0.2 \%)$ in the natural oxygen. Two conclusions were drawn based on the $17 \mathrm{Da}$ peak: 1) The majority of the detected oxygen at 16 and $18 \mathrm{Da}$ originates from $\mathrm{O}^{+}$and not from $\mathrm{O}_{2}{ }^{2+}$, contrary to what is stated in work by Bachhav et al. [21]; 2) The contribution from $\mathrm{O}_{2}{ }^{2+}$ accounts for approximately $1 \%$ of the total oxygen content using the analysis conditions in this work. The presented values in Table 1 include correction of this aspect.

Figure 8 (a) shows a section of an APT reconstruction obtained near the very end of the crack, where the interface region between a closed crack-tip oxide and metal is presented. Selected oxides are visualized in Figure 8 (a), the succession from oxide to metal (left to right) is: Ni-rich oxide (green); $\mathrm{Ni} / \mathrm{Fe}-$ rich oxide (blue); $\mathrm{Cr}$-rich oxide (red) and finally $\mathrm{Cr}$ in the metal (grey). $\mathrm{Al}$ and $\mathrm{Nb}$ rich oxides are not visualized in Figure 8 (a), however, they are present as thin discontinuous layers near the interface between the Cr-rich oxide and the metal. In the same region also a slightly increased level of B was found. The compositional profiles in Figure 8 (b), (c) and (d) were acquired in the direction of the arrow in (a). These results are in general agreement with those from TEM and XPS studies, however, APT unveils far more detailed aspects of the oxides. Table 1 shows the average compositions of the oxides in the total analysis volume and also the composition of the near-oxide metal. The composition of untested material is also shown here for comparison. 
The outermost oxide is $\mathrm{Ni} / \mathrm{Co} / \mathrm{Fe}$-rich with regions of more Ni-rich oxide, nearly stoichiometric $\mathrm{NiO}$ (the latter shown as green in Figure 8 (a)). These Ni-rich regions show highly similar size, morphology and spatial distribution as the $\mathrm{Ni}_{3}(\mathrm{Al}, \mathrm{Nb}) \gamma^{\prime}$ precipitates in untested material. c.f. Figure 4 (a). It is therefore reasonable to state that $\gamma^{\prime}$ precipitates have oxidized to NiO. Approaching the metal the Co-content decreases and the oxide becomes distinctly Fe- rich ( $\mathrm{Ni}$ is however still the major constituent). This signifies the $\mathrm{Ni} / \mathrm{Fe}$-rich oxide that surrounds the $\mathrm{NiO}$ regions with morphology notably similar to that of the unoxidized matrix. It is noteworthy that the stoichiometry of the $\mathrm{Ni} / \mathrm{Fe}$ rich oxide is different from the $\mathrm{Ni}(\mathrm{FeCr})_{2} \mathrm{O}_{4}$ spinel reported by Andrieu et al. [22] and Sennour [23] in similar studies. The inner Cr-rich oxide shows an $\mathrm{M}_{2} \mathrm{O}_{3}$-type composition where $\mathrm{Cr}$ is clearly the single dominant metal specie. This oxide overlaps spatially somewhat with the $\mathrm{Al}$ and $\mathrm{Nb}$-rich oxides in the immediate vicinity of the metal. These Al- and Nb-rich oxides are believed to form by oxidation of $\gamma^{\prime}$-precipitates at the oxide/metal interface following the formation of the outer oxides that would yield the low oxygen partial pressure $\left(P_{\mathrm{O}_{2}}\right)$ below the Cr-rich oxide layer that promote preferential oxidation of $\mathrm{Al}$ and $\mathrm{Nb}$. The partially oxidized precipitates near the interface (see Table 1) support this theory. Precipitates further into the metal away from the oxide were essentially unaffected.

Distinct oxygen-rich finger-like protrusions from the oxide into the underlying metal were observed (see Figure 9, same APT analysis volume as Figure 8). These protrusions showed an average oxygen content of approximately 27 at.\%. Moreover the Al content in these volumes ( 5.5 at.\%) was found higher than that in the surrounding matrix (1.7 at.\%). The lengths of the protrusions were observed to be up to $20 \mathrm{~nm}$ and they were consistently found in the matrix rather than the precipitates.

\section{Discussion}

\section{Oxidation at the crack tip}

The sustained load cracks were found oxidized in approximate accordance with the four-zone model previously presented [19]. The front most oxide is closed over a length of approximately $1 \mu \mathrm{m}$ and was found layered (in contrast to that previously reported [19] where the closed oxide was estimated to consist of a single oxide type, though with regions of unknown character). The oxide layering is consistent throughout the length of the intergranular crack: The inner oxide (near the metal) is dominantly Cr-rich and the outer oxide (near the prior grain boundary, now oxidized) is Ni-rich with locally varying composition. This suggests that oxygen has reasonably easy access to the very crack tip through the closed Ni-rich oxide that is not dense and thereby offers rapid diffusion paths. This is supported by the high ${ }^{18} \mathrm{O}$ signal at the crack tip in SIMS analyses (Figure 3), the structurally intact but defect-rich oxide structure observed by TEM (Figure 6) and the presence of Ni-rich oxide near the very tip of oxide (also Figure 6) for the formation of which a relatively high oxygen partial pressure is required.

The proposed course of events at the crack tip is as follows: When oxygen enters the grain boundary, due to its low solubility in the alloy, it reacts rapidly (within seconds) with the least noble and most active elements such as $\mathrm{Ni}$ and $\mathrm{Fe}$ to form dominantly Ni-rich oxide. According to Andrieu et al. [22] such oxide may form at $P_{O_{2}}$ values down to $10^{-4}$ torr for a similar system (Alloy 718 at $650{ }^{\circ} \mathrm{C}$ ). This Ni-rich oxide is not dense and therefore allows further oxygen transport to the grain boundary ahead of the oxide and also to the grains flanking the crack. However, due to the faster oxygen diffusion along the grain boundary the oxide growth is faster in this direction. This is supported by the length of the closed oxide along the oxidized grain boundary which is in the order of $1 \mu \mathrm{m}$ whereas the flanking oxides are some tens of nanometres thick in the same region. As the Ni-rich oxide layers grow the oxygen partial pressure below these decreases, favouring oxidation of species such as $\mathrm{Cr}$ and then $\mathrm{Nb}$ and $\mathrm{Al}$, capable of forming stable oxides at lower $P_{\mathrm{O} 2}$. These oxides are generally denser and therefore offer better protection against further oxidation. Thus, the observed presence of Cr-rich oxide ahead the crack (Figure 6 (b)) is considered beneficial from a oxidation resistance point of view. 
The oxide layering is in good agreement with thermodynamic predictions with regard to the sequence of required $P_{\mathrm{O} 2}$ for oxidation of the dominant oxide-forming species and is also good agreement with other studies [23, 24]. However, in the three-dimensional APT analyses the high spatial resolution reveals the structure not to be strictly layered as local heterogeneities are present within and inbetween the oxide layers. The APT results show that the Ni-rich oxide does not have a homogeneous composition, see Table 1. Rather, it consists of three distinct regions: a Co-enriched outermost layer; inner $\mathrm{Fe}$-enriched regions originating from the oxidized matrix; volumes with $\mathrm{NiO}$ stoichiometry originating from oxidized $\gamma^{\prime}$ precipitates. Apart from $\mathrm{Ni}$, none of the primary $\gamma^{\prime}$-related species $\mathrm{Al}$ and $\mathrm{Nb}$ are distinctly present in the NiO-regions and thus the question arises: what happens to these elements?

According to the Ellingham diagram, Co oxidizes at the highest $P_{O_{2}}$ of these elements while Al and $\mathrm{Nb}$ oxidize at the lowest. It is thus suggested that the high Co content (c.f Table 1) in the outer $\mathrm{Ni} / \mathrm{Co} / \mathrm{Fe}$-rich oxide is supplied by both $\gamma^{\prime}$ precipitates $(4.0 \mathrm{at} \%$ in the untested condition) and the matrix (11.3 at.\%). Al from the oxidized $\gamma^{\prime}$ precipitates is partially found in the $\mathrm{Ni} / \mathrm{Fe}$ oxide that surrounds the NiO-regions (3.7 at $\%$, compared to 0.7 at. $\%$ in untested matrix) and partially below the $\mathrm{Cr}$-rich oxide. $\mathrm{Nb}$ is primarily found in the inner part of the $\mathrm{Cr}$-rich oxide. It appears as if these elements where expelled from $\gamma^{\prime}$ during the oxidation.

Oxygen-rich protrusions (Figure 9) were observed to extend into the otherwise unoxidized matrix. It is suggested that these protrusions are caused by the preferential rapid oxygen diffusion along defects, presumably dislocations given the observed plastic deformation in the crack tip region. They moreover contribute significantly to the total oxygen level seen in the near the oxide/metal interface in Figure 8 (b). This makes detailed quantification of oxygen levels in the metal intricate. For the APT analyses, also so-called ion trajectory effects may contribute to the high amount of $\mathrm{O}$ by causing signals from the two different regions to be mixed close to the interface (here the oxide and metal). The NanoSIMS analysis shown in Figure 2 (b) does not offer such high spatial resolution as APT but there is a distinguishable difference in ${ }^{18} \mathrm{O}$ signal intensity over the grain boundary oxide. The signal also seems to stem from a broader area than the SEM BSE dark contrast (of the oxide) in in Figure 2 (a). Both effects may partially derive from beam size effects in the NanoSIMS, however, the combination of NanoSIMS and APT results suggest that oxygen penetration into the matrix over some tens of nanometres cannot fully be excluded.

\section{Oxide growth and kinetics}

The measured NiO: $\mathrm{Cr}_{2} \mathrm{O}_{3}$ thickness ratios (Figure 7) indicate that once the $P_{O_{2}}$ is sufficiently low to allow oxidation of $\mathrm{Cr}$, the $\mathrm{Cr}_{2} \mathrm{O}_{3}$ scale initially grows rapidly and essentially becomes fully protective somewhere between 300 and $3000 \mathrm{~s}$. Andrieu et al. [22] have estimated the time required for a fully protective scale to form to be approximately $600 \mathrm{~s}$. The fact that the $\mathrm{NiO}$ scale has also grown between 300 and $3000 \mathrm{~s}$ indicates that the incomplete $\mathrm{Cr}_{2} \mathrm{O}_{3}$ oxide is not only somewhat permeable to inward oxygen transport, but also allows outward diffusion of metal cations to sustain a slow $\mathrm{NiO}$ formation. The formation of the Cr-rich oxide causes $\mathrm{Cr}$ in the matrix to be depleted. The diffusion coefficient for $\mathrm{Cr}$ was estimated by numerically solving Fick's second law in 1D (assuming a concentration independent diffusion coefficient $D$, see Eq. (1)) for different values of $D$ under the assumption of a stationary interface, and comparing with the experimental concentration profiles in Figure 8 .

$$
\frac{\partial c}{\partial t}=D \frac{\partial^{2} c}{\partial x^{2}}
$$

Initially a homogeneous distribution of $\mathrm{Cr}=28.7$ at.\% was assumed based on Table 1. Fixed boundary conditions were used to define the concentration at the $\mathrm{Cr}_{2} \mathrm{O}_{3}$ /matrix interface and in the bulk (set to $100 \mathrm{~nm}$, which was shown to be sufficient not to affect the solution) to 10.6 at.\% and 28.7 
at.\%, respectively. The best fit was obtained for $D=8 \cdot 10^{-18} \mathrm{~m}^{2} \mathrm{~s}^{-1}$ and the resulting calculated $\mathrm{Cr}$ profile after $30 \mathrm{~s}$ is shown in Figure 10 together with the experimental APT Cr profile in Figure 8 (c). The obtained value of $D$ can be compared to work by Chen et al. [25] for surface oxidation of Ni-Cr$\mathrm{Fe}$ alloys at $997 \mathrm{~K}$ where Cr-diffusivity of $10^{-19} \mathrm{~m}^{2} \mathrm{~s}^{-1}$ was reported. The difference of approximately two orders of magnitude is assumed to reflect the effect of applied load and deformation around the crack tip. Similar effects are expected to apply for oxygen diffusion, as it has been shown in the work of Berger et al. [26] that oxygen diffusivity in $\mathrm{NiO}$ increases by two orders of magnitude under a constant stress.

It should be noted that due to the nature of the solution to Eq. (1), the obtained value of $D$ will be inversely proportional to the assumed diffusion time. Hence, the obtained optimum value of $D$ is rather sensitive to the value of the diffusion time chosen in the analysis. However, to achieve a value of $10^{-19} \mathrm{~m}^{2} \mathrm{~s}^{-1}$ the diffusion time must be approximately two orders of magnitude larger than the present estimation of $30 \mathrm{~s}$, which is unfeasible given that the total sustained load time used was $600 \mathrm{~s}$. If assuming that the estimation is off by a factor of two, the resulting diffusion coefficient is still 50 times higher than expected. It can thus be concluded that even if the precise value of $D$ is intricate to calculate, there is a significant increase in the diffusion rate of $\mathrm{Cr}$ that can be attributed to the applied tensile stress.

For the above, the increase of the value of $D$ can be regarded to be an effect of stress and deformation yielding enhanced diffusivity: the crystallographic lattice is subjected to a tensile stress which increases the interatomic distances and as such reduces the energy barrier for diffusion. Another effect of an applied stress is the potential for stress driven diffusion which occurs up-hill with respect to a stress gradient. Under such circumstances, the stress enhanced diffusion process is expressed as

$$
\frac{\partial c}{\partial t}=D \frac{\partial^{2} c}{\partial x^{2}}-\kappa_{C r} D \frac{\partial}{\partial x}\left(c \frac{\partial \sigma}{\partial x}\right)
$$

where $\kappa_{C r}$ is the Cr mobility and $\sigma$ is the stress. In brittle high-strength materials the stresses and elastic strains can be very high in the vicinity of the crack tip as a result of the stress concentration with a singularity at the tip. In such cases the stress gradient can be very large, giving a considerable contribution to the over-all diffusion rate. In the present case, however, the volume of material considered in the diffusion process is small (tenths of micrometres) in comparison to the plastic zone that encloses it (in the order of hundreds of micrometres) and the stress gradient at that scale can be assumed to be small, even if the stresses are high. On the other hand, the local plasticity around the crack tip will give rise to increased dislocation density that allows rapid diffusion along the dislocation cores. The influence of dislocation pipe diffusion on the overall diffusion rate is difficult to describe. Ghonem et al. [27] applied Whipples solution [28] to a diffusion problem described by a slab of material with short-circuit diffusion in a pipe with radius $\delta$, assuming that the pipe diffusion is much faster than diffusion in the matrix, to obtain an expression of the form:

$$
c(x, t)=c_{0}\left\{\operatorname{erf} \frac{\eta}{2}+\frac{\eta}{2 \sqrt{\pi}} \int_{1}^{\Delta} \frac{\mathrm{d} u}{u \sqrt{u}} \exp \left(-\frac{\eta^{2}}{4 u}\right) \operatorname{erf}\left[\frac{1}{2}\left(\frac{\Delta-1}{\Delta-u}\right)\left(\frac{u-1}{(1-\Delta) \xi}-\xi\right)\right]\right\}
$$

where $c_{0}$ is the matrix content, $\eta=x / \sqrt{D t}, \xi=-\delta / \sqrt{D t}, \Delta=D_{d} / D_{m}$ and $D_{d}$ and $D_{m}$ are the diffusion coefficients for pipe and matrix diffusion, respectively. The pipe cross-section in this model corresponds to the sum of the individual dislocation cores available for diffusion. Such an expression cannot be used for quantitative modelling in a straight-forward fashion, since the values of $D_{d}$ and $\delta$ are difficult to estimate. However, it can easily be shown that the pipe radius will have a dominating influence on the total diffusion rate, compared to $D_{d} / D_{m}$, which indicates that an increased dislocation density will have a large effect on the effective $D$. Presumably, the dominant contribution in the present case is the increased contribution from pipe diffusion, given the increased dislocation 
density and plastic zone about the crack, rather than the stress induced lattice expansion. The relative contributions are however very difficult to quantify.

The fact that the protrusions observed in Figure 9 (that are presumed to be dislocations) show very high oxygen concentrations also indicate that the diffusion of oxygen likewise takes place along dislocation lines. However, rapid formation of $\mathrm{Cr}_{2} \mathrm{O}_{3}$, as indicated by the $\mathrm{Cr}$-rich oxide along the dislocation lines, will hinder long-range diffusion even along such rapid diffusion paths, especially since the dislocations likewise serve as outwards diffusion paths for $\mathrm{Cr}$.

\section{Conclusions}

- A dominantly layered oxide structure is formed in the intergranular cracks, with an outer dominantly Ni-rich oxide (near the prior, now oxidized, grain boundary) and an inner dominantly Cr-rich oxide near the metal. The layering sequence is in good agreement with thermodynamic predictions.

- APT analyses reveal that the alloy matrix does not oxidized in the same way as the $\mathrm{Ni}_{3}(\mathrm{Al}, \mathrm{Nb}) \gamma^{\prime}$ precipitates, that oxidize to $\mathrm{NiO}$.

- A Cr-depleted (vis-à-vis Ni-enriched) zone in the metal surrounds the oxide immediately below the inner $\mathrm{Cr}$-rich layer.

- No micron-scale oxygen enrichment was observed at the crack tip, neither in grain boundary ahead of the crack nor in the flanking grains. However, the combined results from APT and SIMS indicate oxygen enrichment to occur over some $20 \mathrm{~nm}$ below the Cr-rich scale and that oxygen diffusion into the metal is enhanced by crystallographic defects.

- Diffusion of $\mathrm{Cr}$ was estimated to be faster than expected from predictions. The increase (two orders of magnitude) is believed to be caused by the applied mechanical load and the resulting plastic and/or elastic deformation. Oxygen diffusion is likewise expected to be enhanced by the load.

\section{Acknowledgements}

The authors are grateful to Professor Chris Grovenor at the Department of Materials, Oxford University, for collaboration and access to the NanoSIMS instrument. Also, collaborators at SwereaKIMAB (Stockholm, Sweden) are thanked for devising the controlled environment test rig and for the joint effort of mechanical testing.

The work was performed within the Swedish High-Temperature Corrosion Centre and was also supported by the Swedish Governmental Agency for Innovation Systems (VINNOVA). 


\section{References}

[1] McMahon CJ, Coffin LF. Met Trans 1970;1:3443.

[2] Ohmura T, Pelloux RM, Grant NJ. Eng Frac Mech 973;5:909.

[3] Woodford DA. In: 4th Bolton Landing Conf, Lake George; 1975:365.

[4] Bricknell RH, Woodford DA. Met Trans A 1981;12A:1673.

[5] King JE. Mater Sci Tech, 1986;3:750.

[6] Woodford DA. Energy Mater 2006;1:59.

[7] Pineau A, Antolovich SD. Eng Fail Analysis 2009;16:2668.

[8] Molins R, Chassaigne JC, Andrieu E. Mater Sci Forum 1997;251-254:445.

[9] Zheng D, Rosenberger A, Ghonem H. Mater Sci Eng A 1993;161:13.

[10] Hippsley CA, deVan JH. Acta Metall 1989;37:1485.

[11] Pfaendtner JA, McMahon CJ. Acta Mater 2001;49:3369.

[12] Hayes RW, Smith DF, Wanner EA, Earthman JC. Mater Sci Eng A 1994;177:43.

[13] Viskari L, Cao Y, Norell M, Sjöberg G, Stiller K. Mater Sci Eng A 2011;528:2570.

[14] Cao WD, Kennedy RL. Acta Metall Sinica 2005;18:39.

[15] Stotter C, Sommitsch C, Wagner J, Leitner H, Letofsky-Papst I, Zickler GA, Prantl W, Stockinger M. Int J Mater Res 2008;99:376.

[16] Pickering EJ, Mathur H, Bhowmik A, Messé OMDM, Barnard JS, Hardy MC, Krakow R, Loehnert K, Stone HJ, Rae CMF. Acta Mater 2012;60:2757.

[17] Xie X, Wang G, Dong J, Xu C, Cao WD, Kennedy R. In: Superalloy 718 and derivatives, Pittsburgh; 2005:179.

[18] Viskari L, Stiller K. Ultramicroscopy 2011;111:652.

[19] Viskari L, Johansson S, Stiller K. Mater High Temp, 2011;28:336.

[20] Seidman DN, Stiller K. An Atom-Probe Tomography Primer. MRS Bull 2009;34:717.

[21] Bachhav M, Danoix R, Danoix F, Hannoyer B, Ogale S, Vurpillot F. Ultramicroscopy 2011;111:584.

[22] Andrieu E, Molins R, Ghonem H, Pineau A. Mater Sci Eng A 1992;154:21.

[23] Sennour M, Marchetti L, Martin F, Perrin S, Molins R, Pijolat M. J Nuclear Mater 2010;402:147.

[24] Molins R, Hochstetter G, Chassaigne JC, Andrieu E. Acta Mater 1997;45:663.

[25] Chen TF, Iijima Y, Hirano KI, Yamauchi K. J Nuclear Mater 1989;169:285.

[26] Berger P, Gaillet L, El Tahhann R, Moulin G, Viennot M. Nucl Instr Methods Phys Res B 2001;181:382.

[27] Ghonem H, Zheng D. Fatigue Frac Eng Mater Struct 1991;14:749.

[28] Whipple, RTP. Phil Mag 1954;45:1225. 
Table 1. Average composition of oxides and bulk metal obtained by APT analysis. Untested bulk metal is additionally shown as reference. Major elements are shown (at. \%).

\begin{tabular}{|l|c|c|c|c|c|c|c|}
\hline Region & $\mathbf{O}$ & $\mathbf{N i}$ & $\mathbf{C o}$ & $\mathbf{F e}$ & $\mathbf{C r}$ & $\mathbf{A l}$ & $\mathbf{N b}$ \\
\hline Ni/Co/Fe-rich oxide & 43.8 & 34.4 & 8.1 & 6.4 & 3.1 & 1.8 & 1.1 \\
\hline Ni-rich oxide & 45.1 & 40.5 & 7.1 & 1.2 & 2.5 & 1.2 & 1.1 \\
\hline Ni/Fe-rich oxide & 48.7 & 18.1 & 6.6 & 13.6 & 7.0 & 3.7 & 1.1 \\
\hline Cr-rich oxide & 58.3 & 9.2 & 2.7 & 2.1 & 18.1 & 4.4 & 4.2 \\
\hline Al-rich oxide & 62.6 & 4.1 & 2.5 & 1.6 & 18.5 & 7.3 & 3.3 \\
\hline Nb-rich oxide & 60.0 & 10.5 & 1.4 & 1.1 & 15.3 & 4.6 & 8.0 \\
\hline \hline Metal near oxide & 4.1 & 61.0 & 9.3 & 5.7 & 12.4 & 1.8 & 2.2 \\
\hline - Matrix near oxide & 2.8 & 55.1 & 11.3 & 7.8 & 17.9 & 1.7 & 1.4 \\
\hline - $\gamma^{\prime}$ near oxide* & 4.5 & 64.4 & 4.3 & 1.3 & 1.6 & 11.2 & 8.3 \\
\hline Untested metal & $<0.01$ & 50.9 & 9.5 & 9.9 & 20.3 & 3.4 & 3.3 \\
\hline - Untested matrix & $<0.01$ & 43.2 & 11.3 & 13.0 & 28.7 & 0.7 & 1.2 \\
\hline - Untested $\gamma^{\prime}$ & $<0.01$ & 69.0 & 4.0 & 1.3 & 0.8 & 10.9 & 9.4 \\
\hline
\end{tabular}

* Average composition of two $\gamma^{\prime}$ precipitates notably affected by oxidation, yet not fully oxidized.

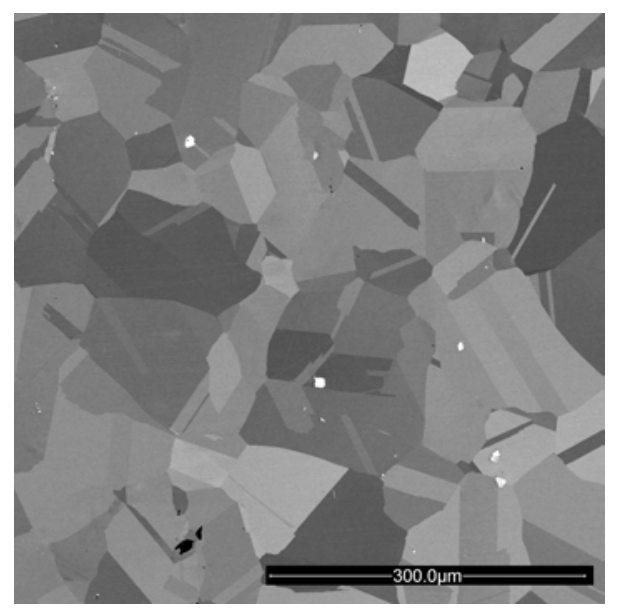

Figure 1. SEM BSE image of the as-heat-treated (untested) microstructure of Allvac 718Plus used in this work.

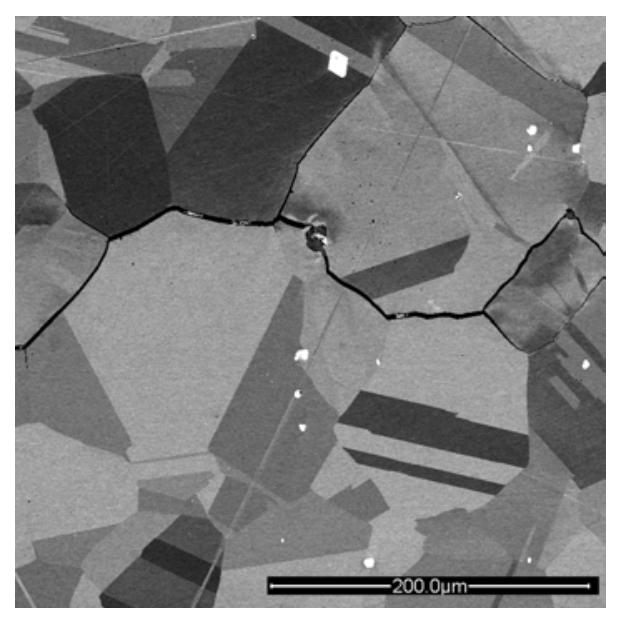

Figure 2: SEM BSE image of an intergranular crack grown under sustained load at $700{ }^{\circ} \mathrm{C}$. Some crack branching can be seen in the adjacent grain boundaries (crack growth direction from right to left). 

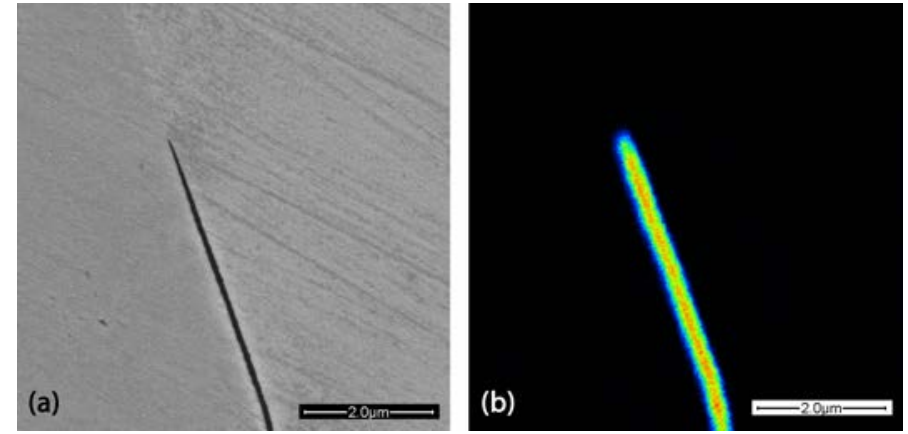

Figure 3. (a) SEM BSE image and (b) SIMS ${ }^{18} \mathrm{O}$ map of an intergranular crack tip. The ${ }^{18} \mathrm{O}$ signal is clearly confined to the crack with no pronounced oxygen diffusion ahead or to the side of the crack at this resolution.

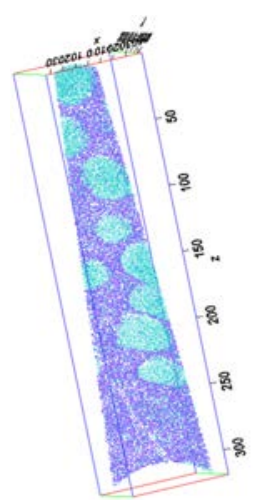

$\mathrm{Cr}$ and $\mathrm{Al}$

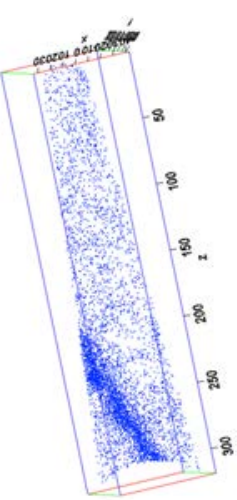

B

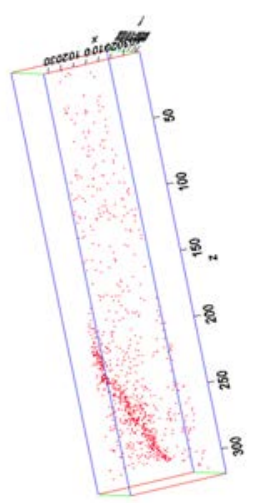

$\mathbf{P}$

Figure 4. APT reconstructions of a grain boundary region within $0.5 \mu \mathrm{m}$ ahead of an oxidized crack tip. In the left figure, $\mathrm{Cr}$ (purple) and $\mathrm{Al}$ (turqoise) indicate the matrix and g' precipitates, respectively. In centre and right figures B (blue) and P (red) are seen to segregate to the grain boundary (please see colour version online).

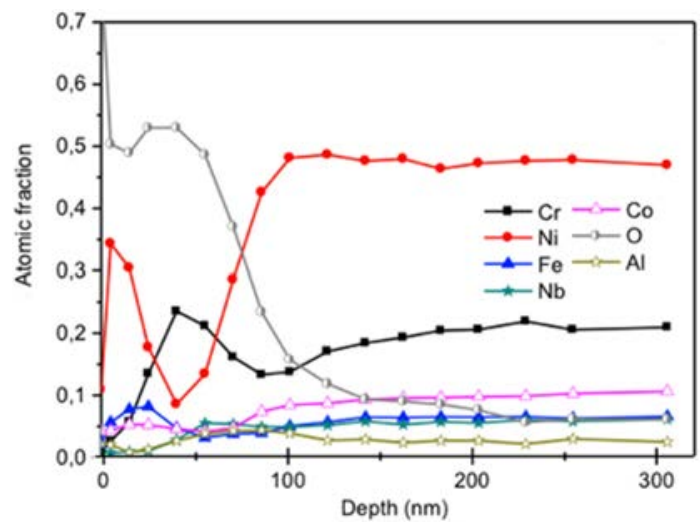

Figure 5. XPS depth profile of the crack surface oxide in the crack wake. The first few nanometres of the depth profile are affected by specimen surface effects and should be disregarded when interpreting the results. Sputtering depth was calibrated using $\mathrm{Ta}_{2} \mathrm{O}_{5}$. Colour version available online. 


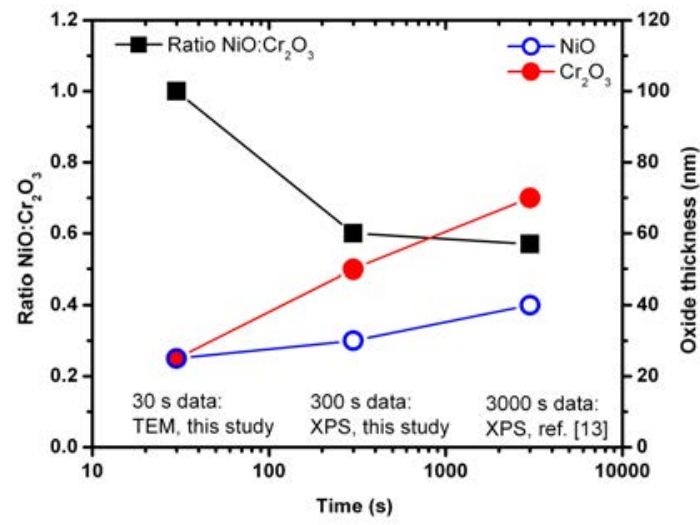

Figure 6. (a) TEM BF image of a closed intergranular oxide at the crack tip. (b) SAED pattern of the oxide with matrix spots blacked out. (c) STEM EDX elemental ratio map of the very tip of this oxide (rotated approximately 45 degrees clockwise), showing Ni-enriched region (green), $\mathrm{Cr}$ and $\mathrm{O}$ at 2:3 ratio (red), $\mathrm{Ni}+\mathrm{Fe}$ and $\mathrm{O}$ at 1:1 ratio (blue). Please see colour version online.
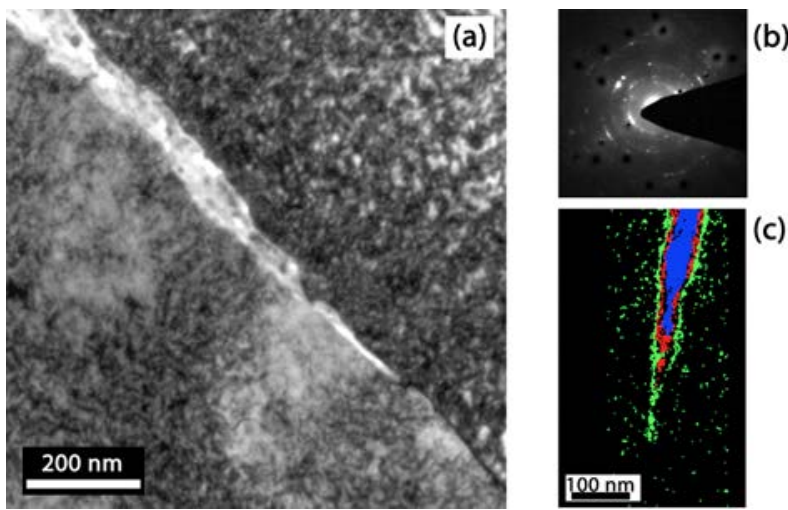

Figure 7. Oxide thicknesses and thickness ratios of $\mathrm{NiO}: \mathrm{Cr}_{2} \mathrm{O}_{3}$ for three different coarsely estimated oxidation times.
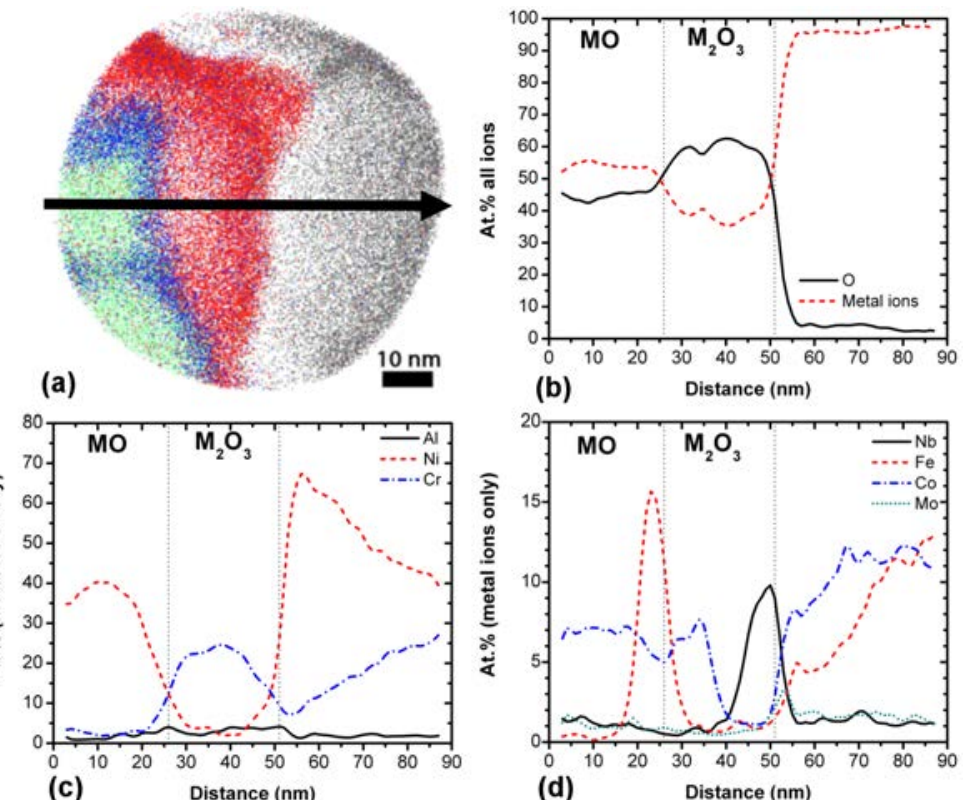

Figure 8. (a) APT reconstruction showing the interface region between metal and a crack tip oxide. See text for description of the oxides. (b-d) Concentration profiles according to the respective legends along the direction shown in (a). Please see colour version online. 


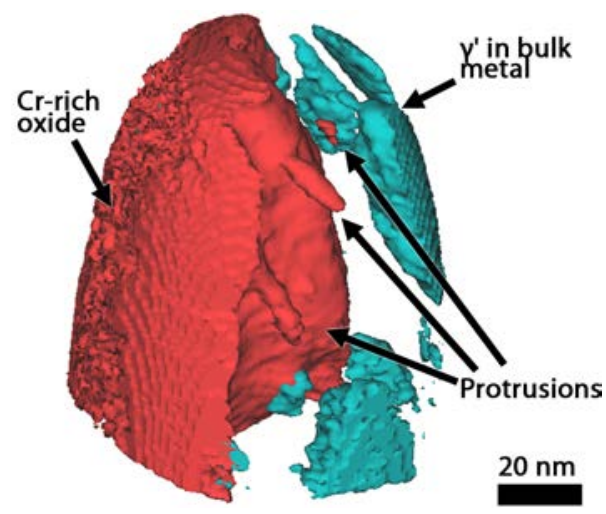

Figure 9. APT reconstruction showing finger-like protrusions from the oxide into the metal. Only Cr-oxide (red, $>4$ ionic $\%$ ) and $\mathrm{Al}$ signals for $\gamma^{\prime}$ precipitates (turquoise, $>6$ at $\%$ ) are shown.

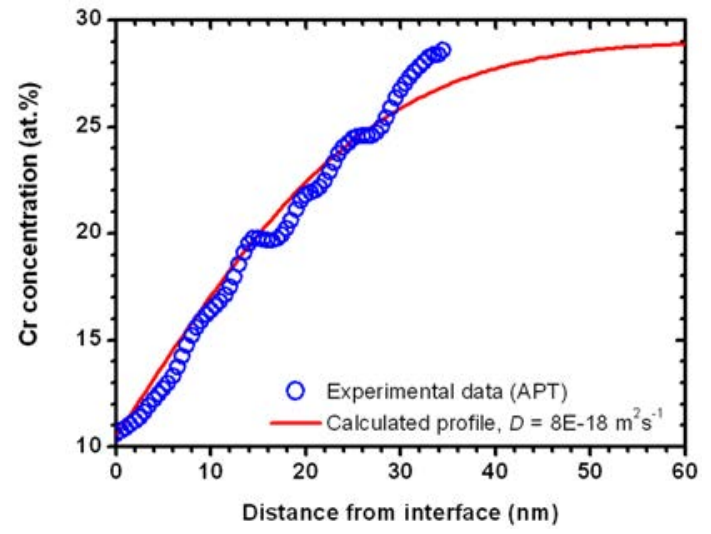

Figure 10. Experimental and calculated $\mathrm{Cr}$ concentration profiles. The calculated profile was obtained with $\mathrm{D}=8 \cdot 10^{-18}$ $\mathrm{m}^{2} \mathrm{~s}^{-1}$, the value giving the best fit between experiment and calculations. Experimental data same as in Figure $8(\mathrm{~b})$. 